\title{
ANALYSES OF LPG DISPERSION DURING ITS ACCIDENTAL RELEASE IN ENCLOSED CAR PARKS
}

\author{
ANALIZA ROZPRZESTRZENIANIA SIE LPG W PRZYPADKU \\ UWOLNIENIA AWARYJNEGO W GARAŻU ZAMKNIĘTYM
}

\begin{abstract}
Despite the fact that LPG (Liquefied Petroleum Gas) is used in a large number of cars, tests have not yet been carried out to ascertain how hazardous can be the release of LPG from the car when parked in enclosed garages. The problem applies to both public and industrial parking areas, especially in Poland, where more than $10 \%$ cars are fueled by LPG. The paper describes full scale experiments, which demonstrate conditions that may occur in a garage in the event of accidental LPG release from the car installation. Over the course of the tests, a series of six LPG spillage tests were performed to study emission time and flammable cloud formation depending on the accidental gap diameter. Additionally, to enable the visual observation of the gas dispersion and influence of the ventilation system the experiment was conducted using well visible $\mathrm{CO}_{2}$ gas cloud, produced from dry ice. The experiments have shown that without ventilation LPG can accumulate on the floor of the enclosed garage for a long time, which generates a high explosive hazard. However, good ventilation (especially jet fan systems) can quickly remove hazardous flammable LPG clouds. Moreover, very important for effective LPG detection is the location of detectors closer to the floor than is currently recommended - at a height of $30 \mathrm{~cm}$.
\end{abstract}

Keywords: LPG, jet fan, ventilation, car park, garage

\section{Introduction}

LPG (Liquefied Petroleum Gas) is the third most popular fuel in the world, with approximately 16 million of passenger cars powered using this fuel, representing about $3 \%$ of the total market share $[1,2]$. It is a mixture of hydrocarbon gases, mostly consisting of propane $\left(\mathrm{C}_{3} \mathrm{H}_{8}\right)$ and butane $\left(\mathrm{C}_{4} \mathrm{H}_{10}\right)$. In winter, LPG mixture contains more propane, while during summer - more butane. The average composition is about $65 \%$ of butane and $35 \%$ of propane. At normal temperature and atmospheric pressure LPG exists in a gas phase. For minimalizing its volume, the gas is liquefied by the high pressure. Vapours can be moved on long distances, reaching a source of ignition where the gas can ignite, flash back or explode. This can create vapour/air explosion hazards indoors or in confined spaces. What is more, the car tanks may rupture if subjected to high temperatures. Approximately half of all autogas-fuelled passenger vehicles are operating in five target markets, which in

\footnotetext{
${ }^{1}$ Faculty of Process and Environmental Engineering, Lodz University of Technology, ul. Wólczańska 213, 90-924 Łódź, Poland, phone +48 4263137 00, fax +48 426368133

* Corresponding author: dorota.brzinska@p.lodz.pl
} 
descending order are Turkey, South Korea, Poland, Italy, and Australia, but the cars are sold in many other countries. The biggest motivation for using LPG in cars engines is the fuel price, which is in average $40 \%$ lower than other fuels. In addition, LPG powered vehicles produce less pollutants from their exhausts in comparison with gasoline- and diesel-fuelled vehicles, which encourages it usage in many countries [1-3]. In Poland, cars with LPG installations are often old and in bad condition, which could be the reason of the accidental gas release. Such gas releases can be dangerous, especially in the underground car parks. The problem is that there is a lack of research into the risk of gaping installations of LPG in garages. Most countries prohibit cars with LPG installation being parked in the underground garages, but this is a very big drawback for their users. In Poland, LPG fuelled cars are allowed entry into underground car parks only if they are equipped with detection and automatic ventilation systems [4]. However, although these systems are required, guidelines for designing them do not exist [5].

There are some studies about the technical problems with LPG transportation, like for example, the methods for the determination of the required safety control levels for this process [6], hazards analysis in the LPG refuelling stations [7], or huge tankers, but there are no publications about the problems associated with relatively small LPG tanks and installations, which exists in cars, and very often are housed in relatively small enclosures car parks [8]. Investigations in Canada showed that human error was the major cause of accidents involving LPG vehicles. The information about 80 accidents was published by Transport Canada's investigation office and the Ontario Ministry of Consumer and Commercial Relations from 1981 to 1986 [9]. Among these, 47 dangerous situations were caused by the human factor, which accounts for $58 \%$ of the accidents [10]. However, fire incidents analyses in Canada have shown that propane fuelled vehicles do not pose an increased fire risk in underground parking areas than gasoline fuelled vehicles [9].

The most important factor for removing pollutants from the enclosure atmosphere is the ventilation systems [11]. In this case, in any opening in the car park construction there also exists atmospheric conditions, where especially wind influence is very significant [12]. Jet fan systems are often applied to support ventilation process in car parks [13]. The jet fans are installed under the ceiling of the enclosure to generate high velocity of air flow. This causes induction of air, and promotes mixing and transporting of the polluted air. The jet fan system is a stream, ductless ventilation system, based on simultaneous action of fans to transport the air or smoke from supply point(s) in the direction of exhaust point(s). While fans are working in first gear, the enclosure is ventilated in the quantities necessary to discharge daily pollutants from cars circulating in the garage. Second gear is used during a fire for smoke exhaust, and also often in the case of LPG detection.

Jet fans are often used in situations where large volumes of air need to be transported with high velocity [13]. However, jet fans were previously used only for tunnels, and premature use in the garages, prior to thorough adaptation to the new destination of car parks [14].

The aim of this study was to determine internal air condition in a car park in the case of accidental LPG release and to evaluate the influence of different ventilation systems on it. The received results and conclusions may be used in all countries where problem with cars powered by LPG exist. 


\section{LPG release time and cloud concentration measurements}

\section{LPG properties}

After gapping the tank or other part of the installation, LPG escapes, evaporates and disperses. Transition of LPG from liquid phase into gas is a very strong endothermic process. Figure 1 shows this situation from an infrared camera, where thee very cold stream of LPG outflow from the car installation is visible.

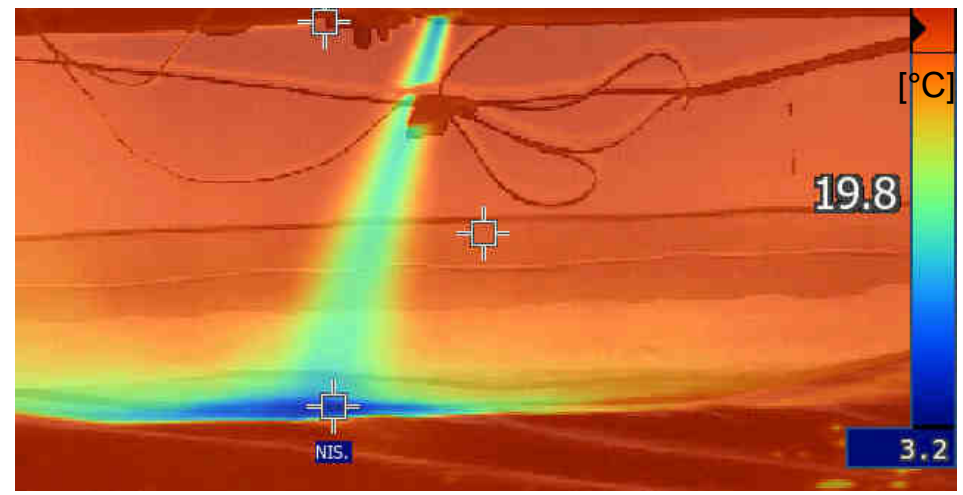

Fig. 1. The gas outflow process from tested car installation - temperature range

LPG at atmospheric temperature and pressure is present as a gas. It is nearly two times heavier than air. The LPG gas has an explosive range of 2 to $10 \%$ volume of gas in the air. This gives an indication of the hazard of LPG vapour accumulated in enclosed car parks in the case of the LPG leakage or spillage from car installation.

The auto-ignition temperature of LPG is around $410-580^{\circ} \mathrm{C}$ and hence it will not ignite on its own at normal temperature, however, it is possible to ignite the cloud of gas phase LPG, through contact with hot car elements, which can reach even $1000^{\circ} \mathrm{C}$. LPG has only a very faint smell, and it often is necessary to add some odorant so that any escaping gas can be very easily detected. LPG, even though slightly toxic, is not poisonous in the vapour phase but can, however, cause suffocation when reach high concentrations, due to the fact that it displaces oxygen. The reason for this is that the vapour possess mild anesthetic properties of LPG.

\section{LPG car installation and the worst case scenarios}

The first part is the installation of fluid phase, the second is the gas vapour. In the part of fluid phase there is the tank and the pipe connecting them with the vaporiser. In the vaporiser LPG is decompressed into the gas phase and goes to the engine. Figure 2 shows the scheme of the typical LPG car installation. In the tank there are multi-valve installed. The multi-valve enables the following:

- $\quad$ blocks the re-fuelling phase at $80 \%$ of the full volume of the cylinder,

- $\quad$ in-takes the LPG when the vehicle is running on gas,

- indicates the amount of LPG in the tank,

- closes the LPG outflow from the tank by means of a solenoid valve when the engine is turned off or in the situation of detection the pressure decrease in LPG installation, 
- $\quad$ keeps safe pressure level in the tank (safety valve, heat-melting pad and overflow valves).

Depending on the volume of the vehicle gas tanks, normally from 35 to $70 \mathrm{dm}^{3}$, according to regulations LPG tanks with their multi-valves need to have actual legalization and are obligatory tested ones a year. The LPG tank is connected with other parts of the installation with the pipe placed under the car. The most popular pipes have $6 \mathrm{~mm}$ diameter and up to $6 \mathrm{~m}$ long. Its standard volume is about $0.17 \mathrm{dm}^{3}$ (Fig. 2).

There are no statistics available on the failure of LPG automotive systems. Based on surveys carried out in the car control stations it was found that unsealed tanks are genarally unheard of and, if a gas leak occurs, it occurs due to a leak from the installation, especially at the connecting points of its parts. This means that if the flow of the whole tank is excluded, the worst case scenario, which was evaluated, is the discharge of the gas from the rest of installation, what means the full volume of the pipe with fluid phase LPG $0.17 \mathrm{dm}^{3}$. Taking into account that from $1 \mathrm{dm}^{3}$ of liquid LPG appears $250 \mathrm{dm}^{3}$ of gas phase LPG, from $0.17 \mathrm{dm}^{3}$ we have $42.5 \mathrm{dm}^{3}$ of pure gas. It thins in the air to $425 \mathrm{dm}^{3}$ of $10 \%$ gas (Upper Explosion Limit - UEL) and later into $2125 \mathrm{dm}^{3}$ of $2 \%$ gas (Lower Explosion Limit - LEL).

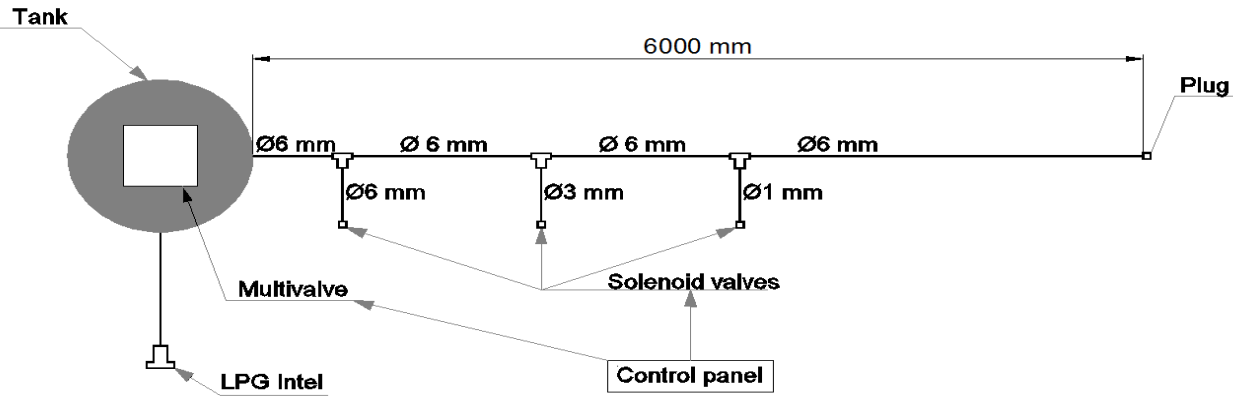

Fig. 2. Scheme of the standard LPG car installation

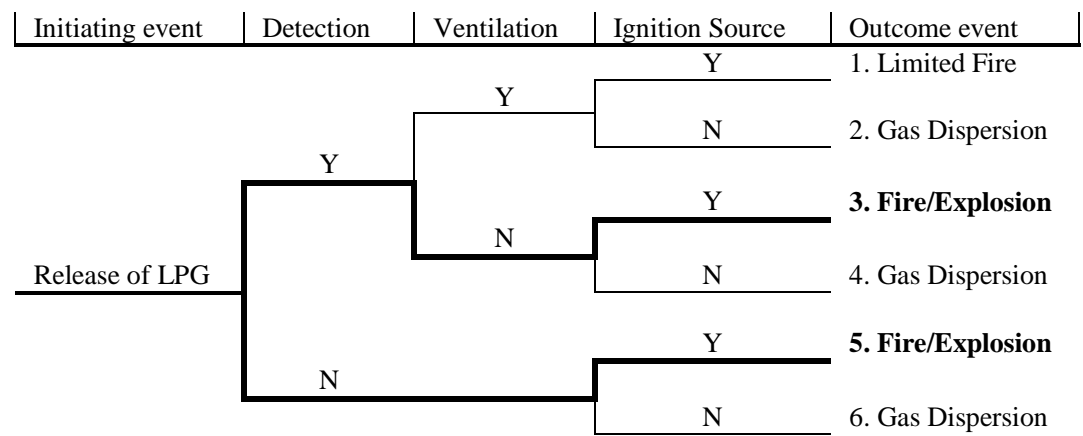

Fig. 3. The event tree used for derivation of possible incident scenarios $(\mathrm{Y}=$ yes, $\mathrm{N}=$ no)

In cases of LPG release, several scenarios are possible. Figure 3 presents the event tree used for derivation of possible incident scenarios. As the initiating event, the release of 
LPG is taken into account, with six different outcomes considered. It is clear that a fire or an explosion are the worst-case scenarios and can be expected in two situations - when ignition source occurs, but only when there is the lack of a detection and ventilation system (black lines on the event tree). If both of the systems works properly (detection and ventilation), only limited fire or gas dispersion are expected.

\section{Measurement layout}

During the experiments, the LPG concentration after release from the car installation was measured. Measurements were carried out in a small car park, on the premises of the 4th State Firefighting and Rescue Unit in Lodz. The research was conducted on a test bench with dimensions of $23.7 \mathrm{~m} \times 4.2 \mathrm{~m}$ and height of $6 \mathrm{~m}$. The test stand was designed and manufactured with regard to ensuring the correct measurement of the LPG propagation in the grid points of measurement. Photograph and scheme of the measurement layout during the research work carried out are shown in Figures 4 and 5. LPG installation was mounted in the passenger car body, showed in Figure 6. LPG concentration was measured by TGS2610 detectors manufactured by Figaro Engineering Inc. (Japan). These are a semiconductor type gas sensors which combines very high sensitivity to LPG gas. Optimal detection concentration of TGS2610 detectors range between 500 and 10,000 ppm of iso-butane and propane.

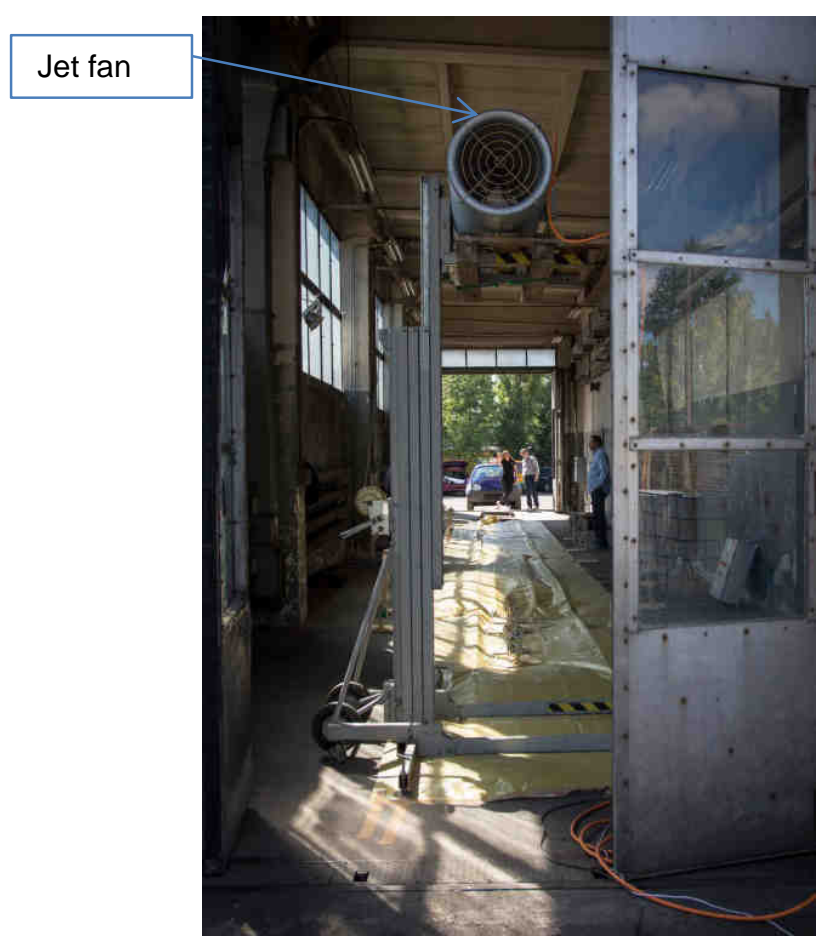

Fig. 4. Photograph of the measurement layout for the LPG propagation 

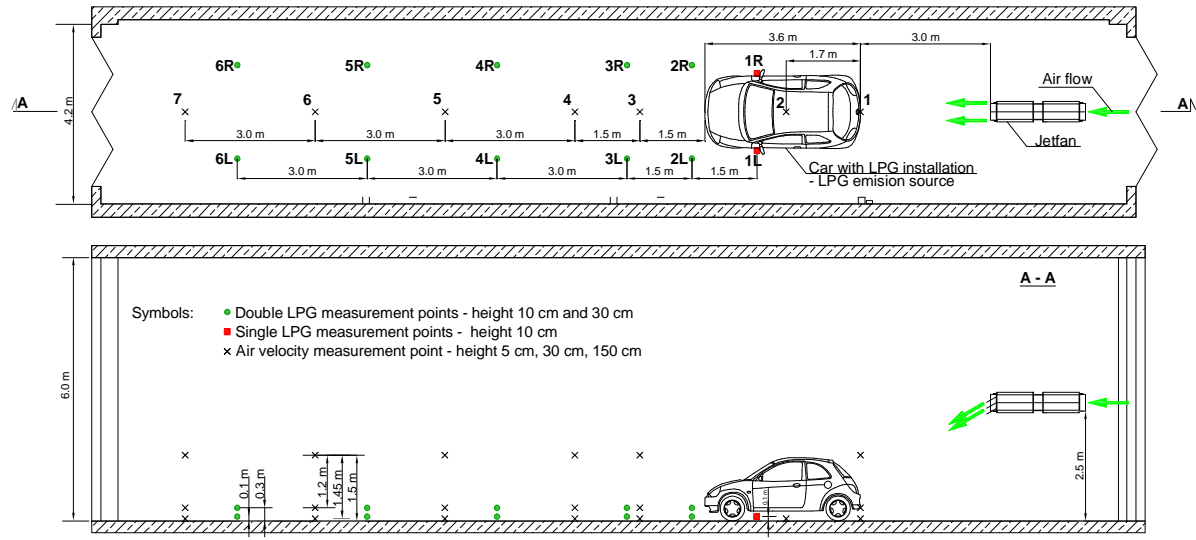

Fig. 5. Scheme of the measurement layout for the LPG propagation

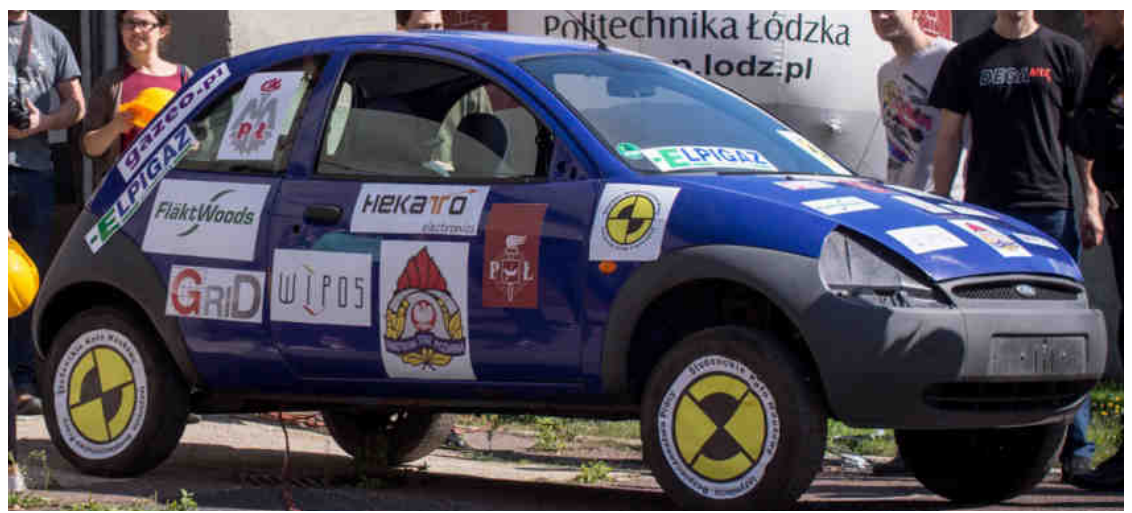

Fig. 6. Photograph of the car body used for the tests

The LPG installation consisted of the LPG tank with the standard multivalve (Fig. 7a) and the pipe carrying the liquid phase LPG, mounted under the car body. The pipe had a $6 \mathrm{~mm}$ diameter and was $6 \mathrm{~m}$ long. In the pipe three solenoid valves were mounted (Fig. $7 b$ ), controlled from the control panel (Fig. 7c). Each solenoid valve had mounted an orifice of a diameter of 1, 3 and $6 \mathrm{~mm}$ respectively. It gave good imitation of various sizes of gaps in the pipe. The scheme of the installation is shown in Figure 2.

The stream ventilation system was realised in the car park with jet fan type; 'LOW-PROFILE 315', manufactured by Fläkt Woods. This was a fan with a diameter of $315 \mathrm{~mm}$, which is most commonly used in underground car parks garages. During the tests of assumed working of ventilation, the ventilator worked in the first gear and had a flow rate of $0.61 \mathrm{~m}^{3} / \mathrm{s}$. The jet fan's guide vanes were sloped towards the floor at an angle of $30^{\circ}$ in relation to the longitudinal axis of the fan. Figure 8 shows a photograph of the jet fan's guide vanes.

Air velocity measurements were carried out at heights of 5, 30 and $150 \mathrm{~cm}$ from the floor. Localisation of measuring points (1-7) is shown in Figure 5. 
a)

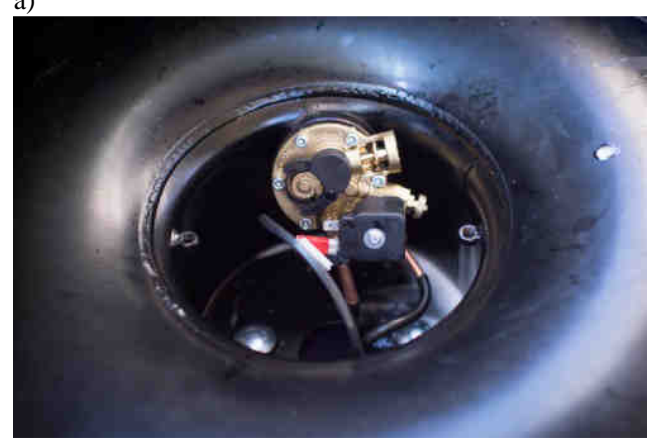

c)

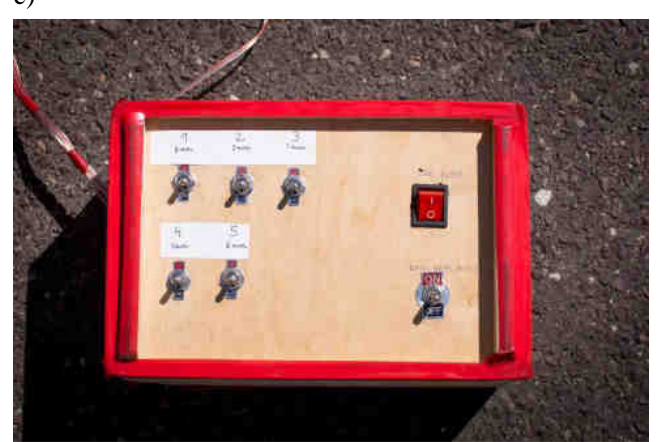

b)

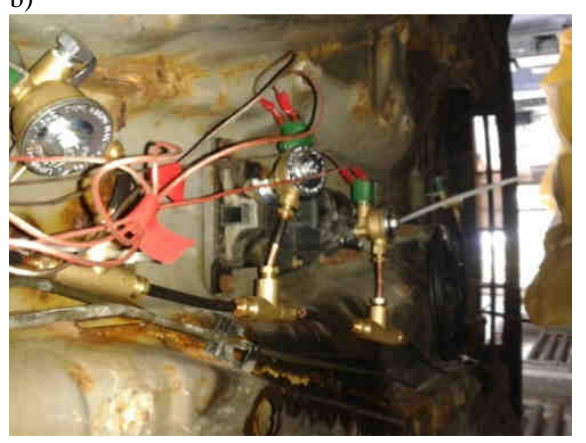

Fig. 7. LPG installation: a) the tank with the multivalve; b) the pipe and three remote-controlled solenoid valves; c) the control panel

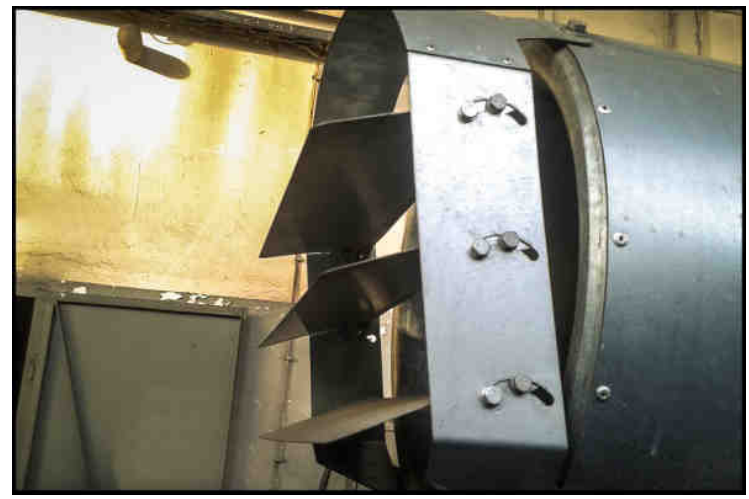

Fig. 8. Jet fan used for the tests and its guide vanes

Air velocity, in the air stream, was measured by using a set of three sensors to measure in terms of lower air flow velocities and air temperatures with telescopic boom type TESTO 0635.1049 connected to the logger TESTO type 454 and cooperating with the PCMCIA card. The velocity range of the sensors was $0-10 \mathrm{~m} / \mathrm{s}$ with an accuracy $<0.01 \mathrm{~m} / \mathrm{s} \pm 5 \%$ of the measured value. Measurements recorded by the meter were developed using computer software company 3 Comsoft TESTO. As a result of the 
measurement, the average velocity of the duration of the measurement amounting to $10 \mathrm{~s}$, at each point in the measurement grid was adopted. Readability of results was $0.01 \mathrm{~m} / \mathrm{s}$. The temperature measurements showed that the conditions of measurements can be considered as isothermal (temperature $20^{\circ} \mathrm{C}$ ). Received air flow velocities are shown in the following graph (Fig. 9).

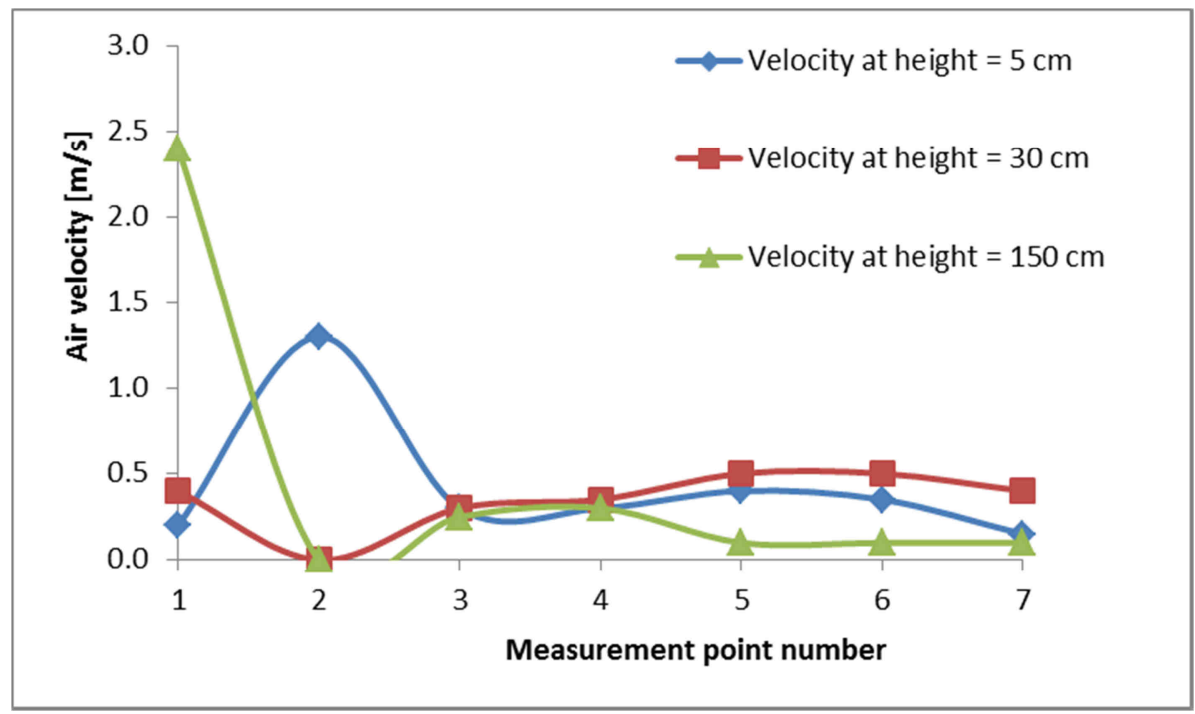

Fig. 9. Air velocity in measurement points 1-7

\section{Measurement results}

To investigate the phenomenon of gas flow from the car installation and its dispersion in the garage six tests were conducted. The first three tests were performed without ventilation. LPG gas was released from the pipe consistent with the scheme in Figure 2, mounted under the car. For each gap diameter $(1,3,6 \mathrm{~mm})$ time of gas flow was estimated. Then all the tests were repeated with the jet fan switched on. The ventilation was switched on at the moment when the detector placed at the distance of $9 \mathrm{~m}$ from the gas source showed the LPG concentration of the level at $10 \%$ of the lower explosion limit. The full turns of ventilator were reached after $20 \mathrm{~s}$ from its switching on. The tests results are shown in Table 1.

Table 1

Gas outflow time and rate and ventilation activation time during the tests

\begin{tabular}{|c|c|c|c|c|c|c|}
\hline $\begin{array}{c}\text { Test } \\
\text { series }\end{array}$ & $\begin{array}{c}\text { Gas } \\
\text { volume } \\
{\left[\mathbf{d m}^{\mathbf{3}}\right]}\end{array}$ & $\begin{array}{c}\text { Diameter } \\
\text { of the gap } \\
{[\mathbf{m m}]}\end{array}$ & $\begin{array}{c}\text { Gas outflow } \\
\text { time }[\mathbf{s}]\end{array}$ & $\begin{array}{c}\text { Gas outflow } \\
\text { rate }\left[\mathbf{d m}^{\mathbf{3}} \mathbf{\text { s}}\right]\end{array}$ & $\begin{array}{c}\text { Ventilation } \\
\text { switch on } \\
\text { time }[\mathbf{s}]\end{array}$ & $\begin{array}{c}\text { Ventilation full } \\
\text { efficiency time } \\
{[\mathbf{s}]}\end{array}$ \\
\hline 1 & 0.17 & 1 & 20.75 & 0.008 & Not active & - \\
\hline 2 & 0.17 & 3 & 5.30 & 0.032 & Not active & - \\
\hline 3 & 0.17 & 6 & 3.95 & 0.043 & Not active & - \\
\hline 4 & 0.17 & 1 & 20.75 & 0.008 & 150 & 170 \\
\hline 5 & 0.17 & 3 & 5.30 & 0.032 & 25 & 55 \\
\hline 6 & 0.17 & 6 & 3.95 & 0.043 & 27 & 57 \\
\hline
\end{tabular}




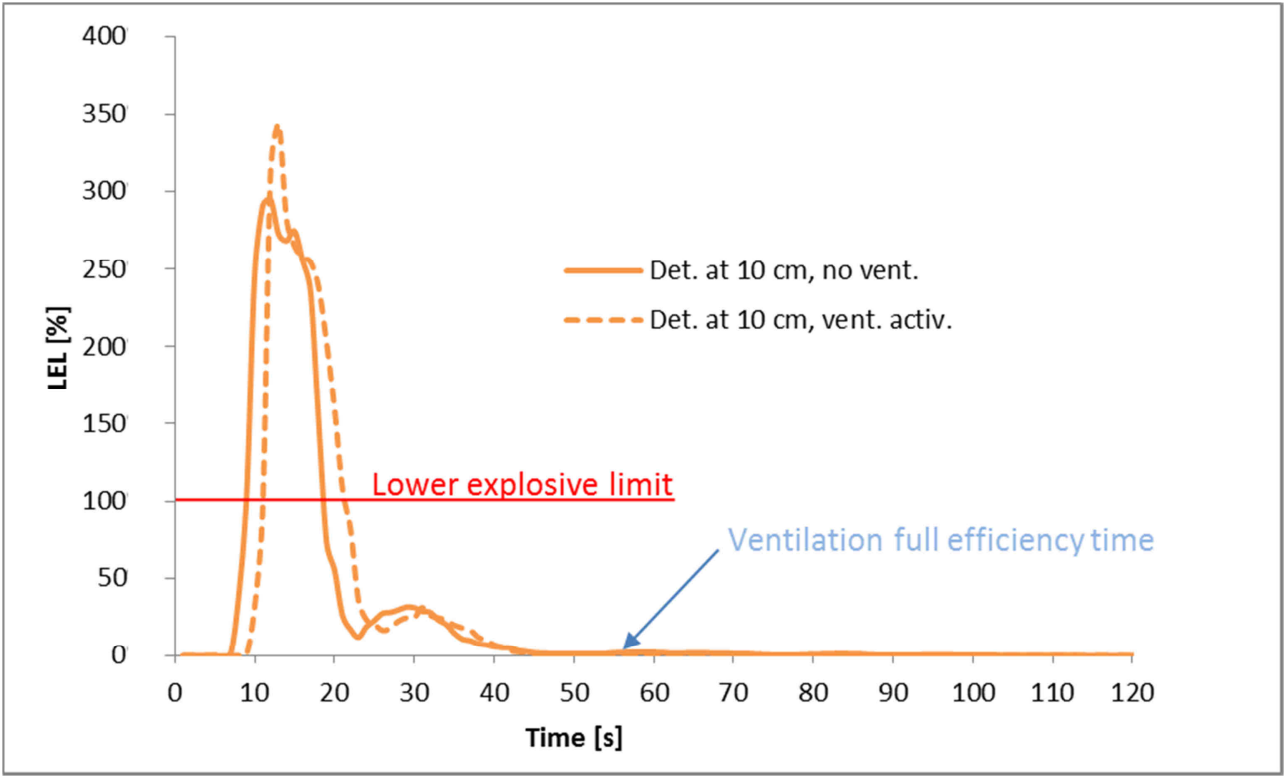

Fig. 10. LPG concentration close to the emission source for $6 \mathrm{~mm}$ gap (measurement point No. 1R)

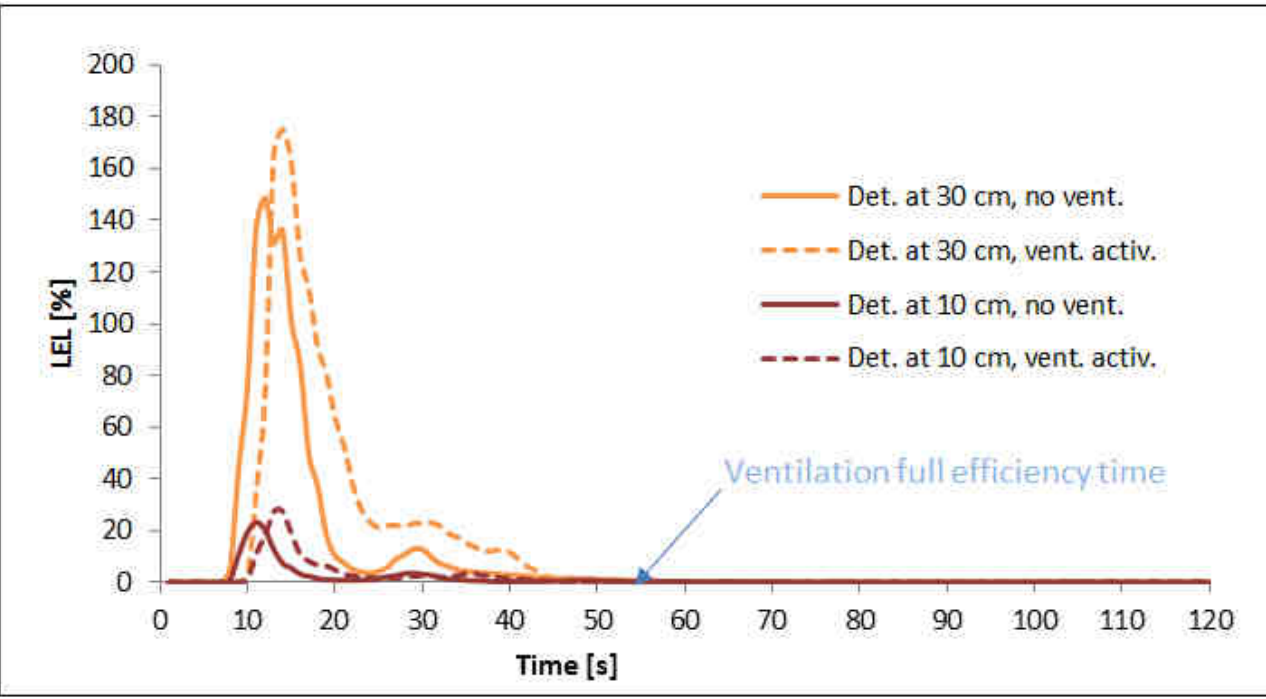

Fig. 11. LPG concentration $3 \mathrm{~m}$ from emission source with $6 \mathrm{~mm}$ gap (measurement point No. 3L)

The highest concentration of LPG was reached close to the source of emission (measurement point No. 1R at Fig. 5). During the test with the biggest gap diameter $6 \mathrm{~mm}$, it reached $350 \%$ of the lower explosive limit, but this was relatively short-lived. The possibilities of explosion (concentration between LEL and UEL) lasted for about 10 seconds and later the concentration of LPG decreased on its own. Figure 10 shows that 
the ventilation system was activated and reached full efficiency in the time when the LPG concentration was very low already. This means that for small LPG releases (as evidenced during the experiment) ventilation systems cannot be influential on the gas dispersion. Similar conclusions can be drawn from the graphs in Figures 11 and 12.

At the greater distance from the LPG source the concentration of gas reached much lower levels and huge difference of gas concentration between detectors localized at 10 and $30 \mathrm{~cm}$ were observed. At a distance of $3 \mathrm{~m}$ from emission source, at the height of $10 \mathrm{~cm}$ concentration was still high, up to about $180 \%$ of LEL, but at $30 \mathrm{~cm}$ it reached only $23 \%$ of LEL (Fig. 11). At a distance $9 \mathrm{~m}$ from emission source differences between concentration at 10 and $30 \mathrm{~cm}$ were smaller and this concentration reached only 10-20\% of LEL (Fig. 12).

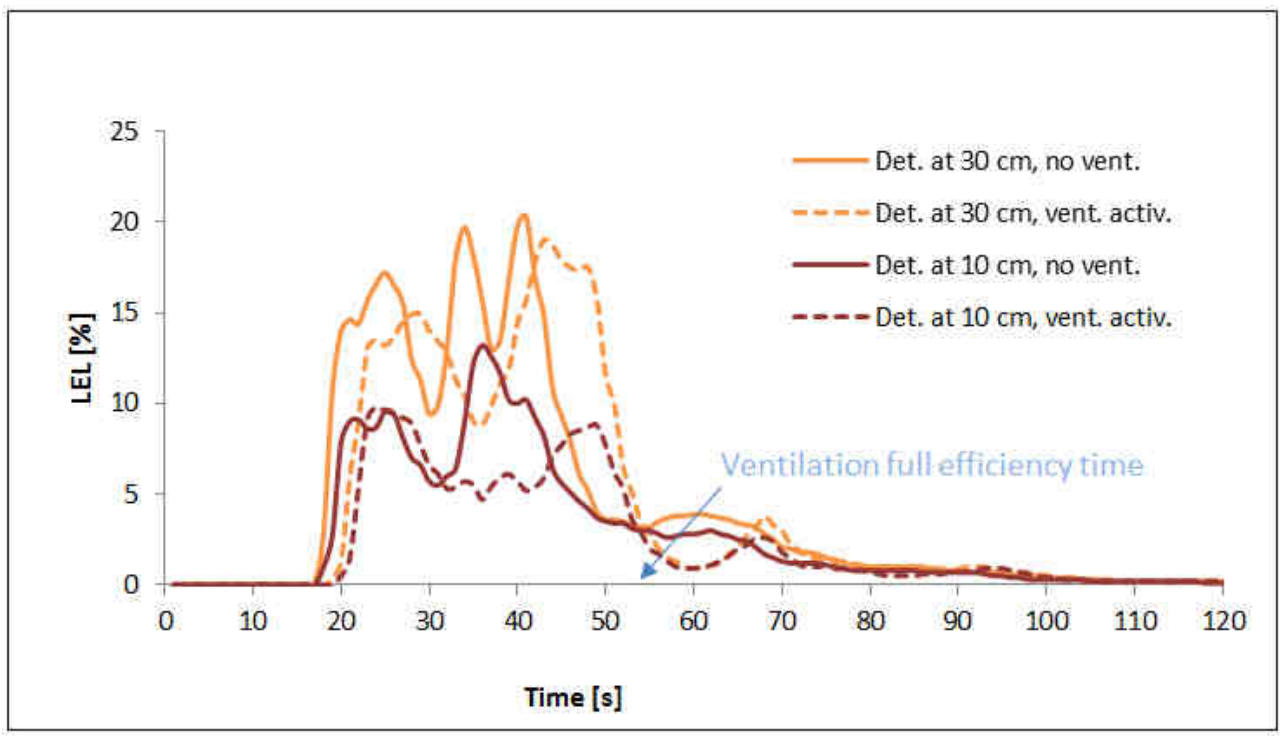

Fig. 12. LPG concentration $9 \mathrm{~m}$ from emission source with $6 \mathrm{~mm}$ gap (measurement point No. 5R)

From the experiments it can be summarized that at a height of $10 \mathrm{~cm}$ the concentration of LPG far exceeds the concentration at $30 \mathrm{~cm}$. It means that there is much higher probability of detection of LPG close to the source of emission and near the floor (Figs. 11 and 12).

The probability of LPG detection was designated on the base of all six tests, taking into account LPG concentrations in all double measurements points (2L-6L and $2 \mathrm{R}-6 \mathrm{R})$. On the base of this, the probability of LPG detection at the height of $10 \mathrm{~cm}$ and $30 \mathrm{~cm}$ were compared. Success was treated as a situation when a detector monitored concentration of $10 \%$ LEL, which is the typical LPG threshold. It was found that detection of LPG at a height of $10 \mathrm{~cm}$ can be on average $40 \%$ more likely than at $30 \mathrm{~cm}$ from the floor. At a bigger distance from the emission source probability of detection drastically decreases (Fig. 13). 


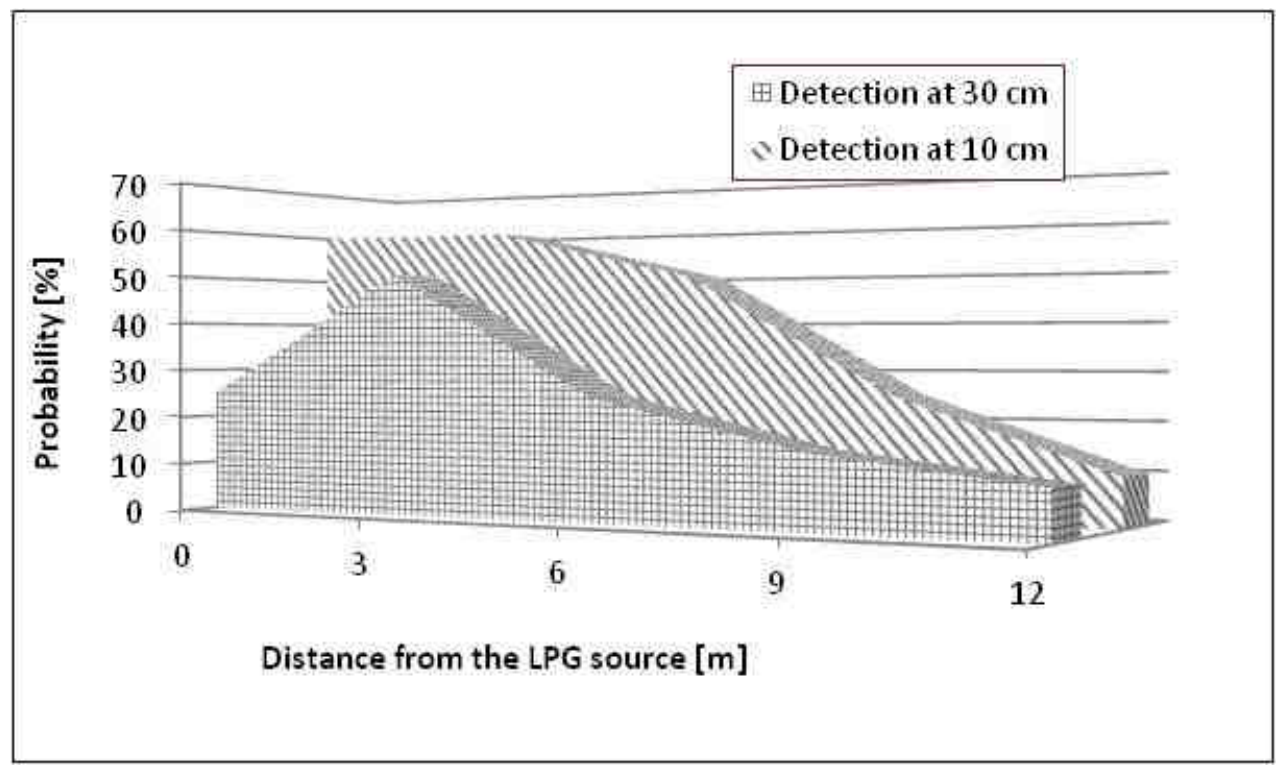

Fig. 13. Probability of LPG detection depending on the height of detectors level

Taking into account results of presented experimental results it is possible to summarise the outcomes as follows:

1. In the case of the LPG accidental release, it is expected a short-time occurrence of an explosive atmosphere ( 10-30 s).

2. The LPG concentration at a height of $10 \mathrm{~cm}$ can far exceed the concentration at $30 \mathrm{~cm}$.

3. There is much higher probability of detection of LPG closer to the source of emission and nearer the floor.

\section{Ventilation effectiveness analyses}

Ventilation system play the most important role in garages in removing pollutants and hazardous LPG gas clouds. There are two possible solutions for installing ventilation systems in the car park:

a) traditional duct system (with $50 \%$ of the total exhaust volume taken near the floor and $50 \%$ under the roof of the garage),

b) Jet fan system.

According to Polish regulations, both ventilation systems may be used and generally the price decides which of them is chosen $[7,13]$. The experiments have shown that in the situation of LPG release, the effectiveness of the traditional duct system can be much lower than from the jet fan system. The tests were conducted in a real industrial car park of $2900 \mathrm{~m}^{2}$ area and $2.7 \mathrm{~m}$ of height. The ventilation systems were installed at this location. According to the duct ventilation rules, $50 \%$ of the total exhaust volume was taken near the floor and $50 \%$ under the roof of the garage. In the jet fan ventilation system the total ventilation capacity was the same as previously, but instead of the ducts, jet fan ventilators were used and the air exhaust were located by only one ventilation point. During the experiment LPG was replaced by dry ice, which generate $\mathrm{CO}_{2}$ cloud, with the parameters of 
gravity and dispersion very similar to the LPG. The test assumed only qualitative evaluation of the ventilation systems.

The experiment results are shown in the photos in Figure 14.

a)

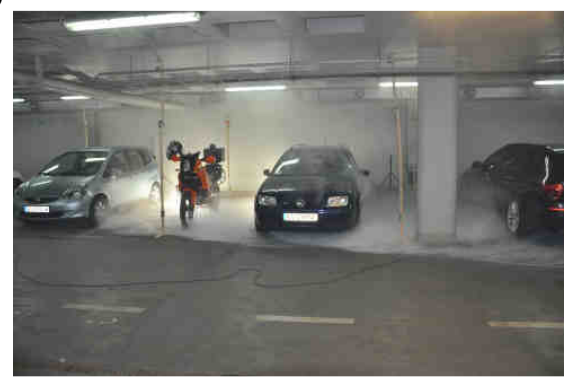

c)

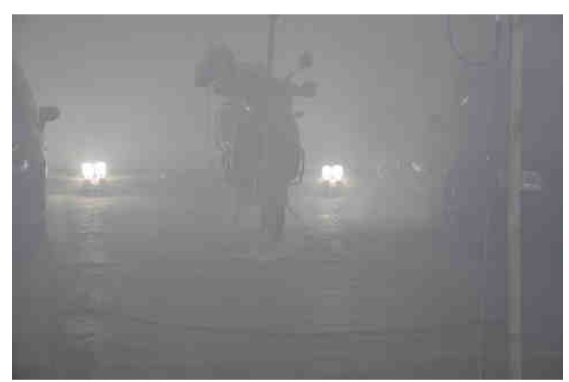

b)

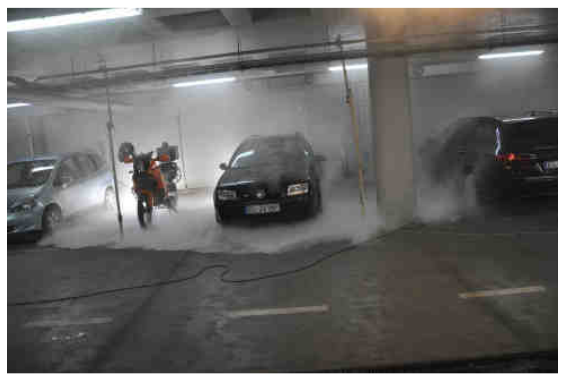

Fig. 14. The ventilation effectiveness test result: a) duct ventilation system - continues work; b) jet fan ventilation system - turn on; c) jet fan ventilation system - continues work

It can be noticed that during the continuing work of duct ventilation system (Fig 14a) the cloud of gas is dispersing on the floor and influence of ventilation cannot be noticed. When the jet fan system turns on (Fig 14b) leaps of the gas can be observed, and after few minutes of continuous operation (Fig 14c) uniform gas density in the full volume of enclosure appeared.

\section{Conclusions}

The real scale tests of accidental LPG release and dispersion in the car park were completed. For the test, the most possible scenario of damage the fluid phase pipe in car installation was assumed. On the basis of the LPG emission full scale tests it was confirmed that in the case of accidental LPG release from the car installation, without efficient ventilation system gas accumulates near the floor of the garage, this can generate a fire and explosive hazards. It was concluded that LPG detectors must be located just above the floor. The proposal to amend the standard detectors localisation from $30 \mathrm{~cm}$ above the floor to $10 \mathrm{~cm}$ has been formulated and submitted to the Polish installation companies. It was also found that ventilation systems operating in the case of LPG accidental release should most efficiently ventilate the lower parts of the garages. It is apparent from the test outcomes that the jet fan ventilation systems and duct systems can be often insufficient for this purpose. The above observations are very important because the duct ventilation and 
high locating LPG detectors are very common in polish underground, enclosed car parks and offer the possibility to enter the cars fueled with LPG, what as demonstrated by studies do not provide a sufficient level of security.

\section{Acknowledgements}

The 4th State Firefighting and Rescue Unit in Lodz is kindly acknowledged for providing a garage in which the measurements were done, Fläkt Woods Sp z o.o. (Warsaw, Poland) - for providing a the jet fan, and Hekato Sp z o.o. providing a the LPG detectors that were applied in the experiments.

\section{References}

[1] Karamangil MI. Development of the auto gas and LPG-powered vehicle sector in Turkey: A statistical case study of the sector for Bursa. Energy Policy. 2007;35:640-649. DOI: 10.1016/j.enpol.2006.01.004.

[2] Van den Schoor F, Middha P, Van den Bulck E. Risk analysis of LPG (liquefied petroleum gas) vehicles in enclosed car parks, Fire Safety J. 2013;57:58-68. DOI: 10.1016/j.firesaf.2012.10.026.

[3] Gerini A, Monnier, G, Bonetto R. Ultra Low Emissions Vehicle Using LPG Engine Fuel. SAE Technical Paper 961079. 1996. DOI: 10.4271/961079.

[4] Brzezinska D, Markowski M. Experimental investigation and CFD modelling of the internal car park environment in case of accidental LPG release. Process Safety Environ Protect. 2016. DOI: 10.1016/j.psep.2016.12.001.

[5] Rozporządzenie Ministra Infrastruktury w sprawie warunków technicznych, jakim powinny odpowiadać budynki i ich usytuowanie (Regulation of the Minister of Infrastructure on the technical conditions of the buildings and their location). DzU Nr 75, poz. 690 z późn. zm.). http://isap.sejm.gov.pl/DetailsServlet? id=WDU20150001422.

[6] Akyuz E, Celikb M. Application of CREAM human reliability model to cargo loading process of LPG tankers. J Loss Prevent Process Industries. 2015;34:39-48. DOI: 10.1016/j.jlp.2015.01.019.

[7] Rajakarunakaran S, Kumar AM, Prabhu VA. Applications of fuzzy faulty tree analysis and expert elicitation for evaluation of risks in LPG refuelling station. J Loss Prevent Process Industries. 2015;33:109-123. DOI: 10.1016/j.jlp.2014.11.016.

[8] Brzezińska D, Markowski AM. Experimental evaluation of LPG release and dispersion in the enclosed car parks. Chem Eng Trans. 2016;48:253-258. DOI: 10.3303/CET1648043.

[9] Armstrong J, Clare J, Garis L. Propane-Fuelled Vehicles and Multi-Residential Building Storage Risk, Examining the Frequency of Propane-Fuelled Structure and Vehicle Fires. University of The Fraser Valley, Centre for Public Safety \& Criminal Justice Research, Canada, January 2013. https://www.ufv.ca/media/assets/criminology/Propane-Fueled-Vehicles.pdf.

[10] Liu E, Yue SY, Lee JA. Study on LPG as a Fuel for Vehicles. Research and Library Services Division Legislative Council Secretariat, Hong Kong; 1997. http://www.legco.gov.hk/yr97-98/english/sec/ library/967rp05.pdf.

[11] Cichowicz R, Sabiniak GH, Wielgosiński G. The influence of a ventilation on the level of carbon dioxide in a classroom at a higher university. Ecol Chem Eng S. 2015;22(1):61-71. DOI: 10.1515/eces-2015-0003.

[12] Cichowicz R, Wielgosiński G. Effect of meteorological conditions and building location on $\mathrm{CO}_{2}$ concentration in the university campus. Ecol Chem Eng S. 2015;22(2):189-200. DOI: 10.1515/eces-2015-0010.

[13] Betta V, Cascetta F, Musto M, Rotondo G. Fluid dynamic performances of traditional and alternative jet fans in tunnel longitudinal ventilation systems. Tunnelling Underground Space Technol. 2010;25:415-422. DOI: 10.1016/j.tust.2010.02.006.

[14] Viegas CJ. The use of impulse ventilation for smoke control in underground car parks. Tunnelling Underground Space Technol. 2010;25:42-53. DOI: 10.1016/j.tust.2009.08.003. 